\title{
GDF11 induces differentiation and apoptosis and inhibits migration of C17.2 neural stem cells via modulating MAPK signaling pathway
}

\author{
Zongkui Wang ${ }^{1}$, Miaomiao Dou ${ }^{1}$, Fengjuan Liu ${ }^{1}$, Peng Jiang ${ }^{1}$, Shengliang Ye ${ }^{1}$, Li Ma ${ }^{1}$, Haijun Cao ${ }^{1}$, Xi \\ Du ${ }^{1}$, Pan Sun ${ }^{1}$, Na Su ${ }^{1}$, Fangzhao Lin ${ }^{1}$, Rong Zhang ${ }^{\text {Corresp., }}{ }^{1}$, Changqing Li ${ }^{\text {Corresp. }}{ }^{1}$ \\ ${ }^{1}$ Institute of Blood Transfusion, Chinese Academy of Medical Sciences \&Peking Union Medical College, Chengdu, Sichuan, China \\ Corresponding Authors: Rong Zhang, Changqing Li \\ Email address: kylie2009@foxmail.com, lichangqing268@163.com
}

GDF11, a member of TGF- $\beta$ superfamily, has recently received widespread attention as a novel anti-ageing/rejuvenation factor to reverse age-related dysfunctions in heart and skeletal muscle, and to induce angiogenesis and neurogenesis. However, these positive effects of GDF11 were challenged by several other studies. Furthermore, the mechanism is still not well understood. In the present study, we evaluated the effects of GDF11 on C17.2 neural stem cells. GDF11 induced differentiation and apoptosis, and suppressed migration of C17.2 neural stem cells. Besides, GDF11 slightly increased cell viability after $24 \mathrm{~h}$ treatment, showed no effects on proliferation for about 10 days of cultivation, and slightly decreased cumulative population doubling for long-term treatment $(p<0.05)$. Phosphoproteome profiling array displayed that GDF11 significantly increased the phosphorylation of 13 serine/threonine kinases $(p<0.01$ ), including p-p38, p-ERK and $p$-Akt, in C17.2 cells, which implied the activation of MAPK pathway. Western blot validated that the results of phospho-proteome profiling array were reliable. Based on functional analysis, we demonstrated that the differentially expressed proteins were mainly involved in signal transduction which was implicated in cellular behavior. Collectively, our findings suggest that, for neurogenesis, GDF11 might not be the desired rejuvenation factor, but a potential target for pharmacological blockade. 
1

2

3

4

5

6

7

8

9

10

11

12

13

14

15

16

17

18

19

20

21

22

23

24

25

26

27

28

29

30

31

32

33

34

35

36

37

38

39

40

34

37

38

GDF11 induces differentiation and apoptosis and inhibits migration of C17.2 neural stem cells via modulating MAPK signaling pathway

Zongkui Wang 1, Miaomiao Dou 1, Fengjuan Liu 1, Peng Jiang 1, Shengliang Ye 1, Li Ma ${ }^{1}$, Haijun Cao ${ }^{1}$, Xi Du ${ }^{1}$, Pan Sun ${ }^{1}$, $\mathrm{Na} \mathrm{Su}{ }^{1}$, Fangzhao Lin ${ }^{1}$, Rong Zhang ${ }^{1}{ }^{*}$, Changqing Li ${ }^{*}$

1 Institute of Blood Transfusion, Chinese Academy of Medical Sciences \& Peking Union Medical College, Chengdu, China, 610052

* Corresponding authors:

Rong Zhang, e-mail: kylie2009@foxmail.com;

Changqing Li, e-mail: lichangqing268@163.com.

14

15

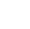

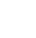

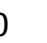

1

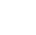

4

6

7

28

0

31

32

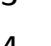


41

42

43

44

45

46

47

48

49

50

51

52

53

54

55

56

57

58

59

60

61

62

63

64

65

66

67

68

69

70

71

72

73

74

75

76

77

78

79

80

81

\section{Abstract:}

GDF11, a member of TGF- $\beta$ superfamily, has recently received widespread attention as a novel anti-ageing/rejuvenation factor to reverse age-related dysfunctions in heart and skeletal muscle, and to induce angiogenesis and neurogenesis. However, these positive effects of GDF11 were challenged by several other studies. Furthermore, the mechanism is still not well understood. In the present study, we evaluated the effects of GDF11 on C17.2 neural stem cells. GDF11 induced differentiation and apoptosis, and suppressed migration of C17.2 neural stem cells. Besides, GDF11 slightly increased cell viability after 24h treatment, showed no effects on proliferation for about 10 days of cultivation, and slightly decreased cumulative population doubling for long-term treatment $(\mathrm{p}<0.05)$. Phospho-proteome profiling array displayed that GDF11 significantly increased the phosphorylation of 13 serine/threonine kinases $(\mathrm{p}<0.01)$, including p-p38, p-ERK and p-Akt, in C17.2 cells, which implied the activation of MAPK pathway. Western blot validated that the results of phospho-proteome profiling array were reliable. Based on functional analysis, we demonstrated that the differentially expressed proteins were mainly involved in signal transduction which was implicated in cellular behavior. Collectively, our findings suggest that, for neurogenesis, GDF11 might not be the desired rejuvenation factor, but a potential target for pharmacological blockade.

(1)

3


82

83

\section{Introduction}

Growth differentiation factor 11 (GDF11), also known as bone morphogenetic protein 11 (BMP11), is a secreted glycoprotein belonging to the transforming growth factor $\beta$ (TGF- $\beta$ ) superfamily (Pepinsky et al. 2017; Walker et al. 2016). GDF11 plays an important role in anterior/posterior axial patterning during embryonic development (Oh et al. 2002). Similar to the negative effects of myostatin (also known as GDF8), which is 90\% homology with GDF11 (Walker et al. 2017), in skeletal muscle, GDF11 acts as a negative regulator of neurogenesis in the olfactory epithelium (Wu et al. 2003) and in the developing spinal cord (Santos et al. 2012).

Recently, Loffredo et al. (2013) suggested that GDF11 was the rejuvenation factor to reverse age-related dysfunction in heart. Subsequently, it was confirmed that GDF11 repaired injured skeletal muscle and improved cognitive function (Katsimpardi et al. 2014; Sinha et al. 2014). However, the rejuvenating effects of GDF11 on heart, skeletal muscle and brain were questioned by a couple of independent studies. Egerman and colleagues (2015) showed that GDF11 supplementation inhibited muscle regeneration and decreased satellite cell expansion in mice, and suggested that GDF11 was not a rejuvenation factor but a potential target for pharmacologic blockade to treat age-related diseases. Hinken et al. (2016) also suggested GDF11 wasn't a rejuvenator of aged murine skeletal muscle satellite cells. In addition, others reported restoring GDF11 in old mice had no effect on cardiac structure or function (Smith et al. 2015). These conflicting studies offer compelling evidence that the effects of GDF11 are contradictory and demonstrate that the effects of GDF11 on neurogenesis are still not completely understood. Therefore, we require an in-depth knowledge of the effects and potential mechanism of action of GDF11 on regulating neural stem cells.

In the present study, we focused on the effects of GDF11 on the cellular behavior of C17.2 neural stem cells (including viability, proliferation, differentiation, apoptosis and migration), the changes in the phospho-proteome and the corresponding signaling pathways. We herein showed that GDF11 promoted differentiation and apoptosis, and suppressed migration of C17.2 cells. Besides, GDF11 stimulated cellular proliferation in a short time (within 24h), whereas high concentrations of GDF11 inhibited proliferation in a long-term cultivation ( $~ 20$ days). Pathwayoriented proteome profiling revealed that GDF11 stimulation significantly activated phosphorylation of 15 proteins, including Smad2/3, Erk1/2, Akt1/2/3, p38, p70S6k, GSK-3 $\alpha / 3 \beta$ and HSP27, which were mainly involved in MAPK signaling pathway. These data demonstrated the effects of GDF11 on neural stem cell (inducing differentiation and apoptosis, and suppressing migration) through the MAPK pathway.

\section{Materials and methods}


118

119

120

121

122

123

124

125

126

127

128

129

130

131

132

133

134

135

136

137

138

139

140

141

142

143

144

145

146

147

148

149

150

151

152

153

\subsection{Agents}

C17.2 neural stem cell line was purchased from zqxzbio (Shanghai, China). Dulbecco's modified Eagle's medium (DMEM; catalog No. SH30022.01), Penicillin-Streptomycin Solution (catalog No. SV30010) and Trypsin (catalog No. SH30236.01) were obtained from Hyclone (Logan, Utah, USA). Fetal bovine serum (FBS; catalog No. 04-121-1A-US) and horse serum (HS; catalog No. 04-124-1A) were purchased from Biological Industries (Beit Haemek, Israel). Recombinant human/mouse/rat GDF-11/BMP-11 (catalog No. 1958-GD-010) and PhosphoMAPK proteome profiler array kit (catalog No. ARY002B) were obtained from R\&D systems (Minneapolis, USA). Dimethyl sulfoxide (DMSO; catalog No. D2650) were purchased from Sigma-Aldrich (St. Louis, USA). NuPAGE LDS loading buffer (catalog No. NP0007) and NuPAGE 4-12\% Bis-Tris gel (catalog No. NP0321BOX) were obtained from Invitrogen (Waltham, USA). Phosphatase inhibitor cocktail (catalog No.HY-K0022) and protease inhibitor cocktail (catalog No. HY-K0010) were from MedChem Express (Shanghai, China). RIPA buffer (catalog No. 89900) was from Pierce (Rockford, USA). Rabbit anti-Smad2/3 (catalog No. 8685S), rabbit anti-p-smad2/Smad3 (catalog No. 8828S), rabbit anti-CREB (catalog No. 9197S), rabbit anti-p-CREB (catalog No. 9198S), rabbit anti-ERK (catalog No.12950S), rabbit anti-p-ERK (catalog No.4377T), rabbit anti-p38 (catalog No.8690S), rabbit anti-p-p38 (catalog No.4511T), mouse anti-nestin (catalog No.33475S), rabbit anti- $\beta$ III-tubulin (catalog No.5568S), rabbit anti-GFAP (catalog No.12389S), rabbit anti- $\beta$-actin (catalog No.4970S), rabbit antiGAPDH (catalog No.2118S) and goat anti-rabbit IgG (catalog No.7074P2) were obtained from Cell Signal Technology (Beverly, MA, USA). Enhanced Cell Counting Kit-8 (CCK-8; catalog No.C0042) and BCA Protein Assay Kit (catalog No.P0010) were obtained from Beyotime Biotechnology (Beijing, China). Enhanced chemiluminescence (ECL; catalog No.32109) was form Pierce (Rockford, USA).

\subsection{C17.2 cell culture}

C17.2 cells were cultured on $25-\mathrm{cm}^{2}$ culture flasks in complete medium (DMEM supplemented with $10 \%(\mathrm{v} / \mathrm{v})$ FBS, 5\% (v/v) HS, $100 \mathrm{U} / \mathrm{ml}$ penicillin and $100 \mu \mathrm{g} / \mathrm{ml}$ streptomycin) at $37{ }^{\circ} \mathrm{C}, 5 \% \mathrm{CO}^{2}$ in a humidified atmosphere. Media were changed every $2-3$ days. After reaching 70-80\% confluence, C17.2 cells were trypsinized and re-seeded at a density of $4 * 10^{4}$ cells $/ \mathrm{mL}$ in complete medium which was changed to starved medium (DMEM supplemented with $0.5 \%$ HS and $1 \% \mathrm{FBS}$ ) one day post seeding. After $6 \mathrm{~h}$ of serum starvation, different concentrations of GDF11 $(0,12.5,25,50$ and $100 \mathrm{ng} / \mathrm{mL})$ were added, respectively.

\subsection{Cell morphology analysis}

C17.2 cells were seeded onto the 24 -well plates at a density of $4 * 10^{4}$ cells/well in $0.1 \mathrm{~mL}$ complete medium. After adherence, complete medium was replaced with starved medium for $6 \mathrm{~h}$ and then, various concentrations of GDF11 were introduced when appropriate. GDF11-untreated 
154

155

156

157

158

159

160

161

162

163

164

165

166

167

168

169

170

171

172

173

174

175

176

177

178

179

180

181

182

183

184

185

186

cells were served as control.

The cell morphology and viability were examined using LIVE/DEAD ${ }^{\circledR}$ viability / cytotoxicity kit (catalog No.L3224) for mammalian cells (Invitrogen, USA) according to the manufacturer's instructions under inverted fluorescence microscope (AXIO, Zeiss, Jena, Germany). The live cells were stained with calcein AM in green, and the dead cells were stained with ethidium homodimer-1(EthD-1) in red.

\subsection{Cell viability and proliferation assay}

Cell viability was assessed by CCK- 8 assay. Briefly, $10 \mu \mathrm{L}$ of CCK-8 agent was added to each well $2 \mathrm{~h}$ before the termination of the experiment. The optical density (OD) values at $450 \mathrm{~nm}$ were determined using SpectraMax M2 ${ }^{\mathrm{e}}$ (Molecular Devices, Sunnyvale, USA). Then, by comparing the absorbance of GDF11-treated and untreated cells, percentage viability was calculated.

For proliferation assay, $1 * 104 / \mathrm{mL}$ cells were seeded in 12 -well plates in triplicates. When the cell cultured to $\sim 80 \%$ confluence (generally 3 days), cells were trypsinized and manually counted using a haemocytometer. Cell population doubling (PD) was calculated using the following formulae:

$$
\text { (1) } P D=\log 2\left(\mathrm{~N} / \mathrm{N}_{0}\right) \text {, }
$$

where $\mathrm{N}_{0}$ represents the number of cells seeded at the initial passage, $\mathrm{N}$ is the final number of cells.

\subsection{Apoptosis assay}

To investigate the apoptosis-inducing effect of GDF11, we identified apoptotic and necrotic cells by Annexin V-FITC and propidium iodide (PI) dual staining using FACScan flow cytometry (Becton-Dickinson, USA). Approximately $1^{*} 10^{5}$ cells were analyzed in each experimental group. The cell populations were distinguished according to their positioning of quadrants: live cells (Annexin $\mathrm{V}-/ \mathrm{PI}-$ ), early/primary apoptotic cells (Annexin V+/PI-), late/secondary apoptotic cells (Annexin $\mathrm{V}+/ \mathrm{PI}+$ ) and necrotic cells (Annexin $\mathrm{V}-/ \mathrm{PI}+$ ).

\subsection{Scratch wound healing assay}

C17.2 cells were cultured with complete medium in a 48-well plate at a density of $5 \times$ $10^{4}$ cells/well. After reaching $\sim 80 \%$ confluence, a single uniform scratch was made by using a $200 \mu \mathrm{L}$ pipette tip along the center of each monolayer. The scratch was lightly washed with PBS twice to remove the detached cells, and then starved medium supplemented with various concentrations of GDF11 was added $(0 \mathrm{ng} / \mathrm{mL}, 12.5 \mathrm{ng} / \mathrm{mL}, 25 \mathrm{ng} / \mathrm{mL}, 50 \mathrm{ng} / \mathrm{mL}$ and $100 \mathrm{ng} / \mathrm{mL}$, respectively). The scratches were monitored at $0 \mathrm{~h}, 12 \mathrm{~h}$ and $36 \mathrm{~h}$ after scratching by taking photos 
187

188

189

190

191

192

193

194

195

196

197

198

199

200

201

202

203

204

205

206

207

208

209

210

211

212

213

214

215

216

217

218

219

220

with inverted microscope to measure the wound closure. The wound closures of various treatments at different time points were calculated with Image J software.

\subsection{RNA extraction and qRT-PCR analysis}

C17.2 cells were cultured on 12 -well plates at a density of $4 * 10^{4}$ cells per well under standard conditions. Upon reaching $80 \%$ confluence, the complete medium was changed to starved medium. After $6 \mathrm{~h}$ of serum starvation, plates were treated with either indicated concentrations of GDF11 (25ng/mL, 50ng/mL and $100 \mathrm{ng} / \mathrm{mL}$, respectively) or vehicle in starved medium for $4 \mathrm{~h}$. Total RNA was extracted from the cultured cells using TRIZOL reagent according to the standard procedure. Total RNA $(1 \mu \mathrm{g})$ was reverse transcribed in a final volume of $20 \mu \mathrm{L}$ in a reaction containing random primers, using iScriptTM cDNA Synthesis kit (Bio-Rad, Hercules, USA). qRT-PCR was done using the Quantitect SYBR Green PCR kit (Qiagen) with a ABI StepOnePlus Real-time PCR system (Applied Biosystems, Foster City, USA). Relative expression was calculated using the $2^{-\triangle} \triangle \mathrm{Ct}$ method by normalizing with GAPDH housekeeping gene expression and presented as fold changes relative to control. The primers for qRT-PCR were synthesized by Beijing Genomics Institute (Shenzhen, China) and the details of primer sequences are shown in Supplementary Table S1.

\subsection{Phospho-proteome profiling array}

Human phospho-MAPK array kit was used to determine the relative levels of phosphorylation of mitogen-activated protein kinases (MAPKs) and other serine/threonine kinases with or without GDF11 treatment. Briefly, C17.2 cells were rinsed with PBS and solubilized with Lysis Buffer 6 (provided in Human Phospho-MAPK Array Kit) at $1 * 10^{7}$ cells $/ \mathrm{mL}$. After rocking gently at $2-8^{\circ} \mathrm{C}$ for $30 \mathrm{~min}$, the lysates were centrifuged at $14,000 \mathrm{~g}$ for $5 \mathrm{~min}$, and the supernatant was collected and detected the protein contents using BCA protein assay. The arrays were blocked by Buffer 5 for $1 \mathrm{~h}$ on a rocking platform shaker. Afterwards, the mixture of sample and detection antibody cocktail were introduced and incubated overnight at $2-8^{\circ} \mathrm{C}$ on a rocking platform shaker. The following day, the membranes were washed three times, and then were incubated in streptavidin-HRP for $30 \mathrm{~min}$ followed by three washes. The protein blots were developed by ECL reagents. Densitometry analysis was measured with the Quantity One software, and the averaged intensity was calculated by subtracting the averaged background signal. The fold change was obtained by comparing GDF11-treated samples with the untreated control (indicated as a value of 1):

Fold change $=$ average intensity $_{(\mathrm{GDF} 11-\text { treated })} /$ average intensity $_{(\mathrm{control})}$.

The respective coordinates of all the antibodies on the arrays and the corresponding phosphorylation sites can be found in "Supplementary Table S2". 
221

222

223

224

225

226

227

228

229

230

231

232

233

234

235

236

237

238

239

240

241

242

243

244

245

246

247

248

249

250

251

252

253

254

\subsection{Western Blot analysis and validation}

C17.2 cells were cultured in 6-well dishes in starved medium with or without GDF11 for $24 \mathrm{~h}$. Then, the cells were lysed in RIPA buffer containing $1 \times$ phosphatase inhibitor cocktail and $1 \times$ protease inhibitor cocktail on ice for $30 \mathrm{~min}$, and centrifuged at $14000 \mathrm{~g}$ for $5 \mathrm{~min}$ at $4^{\circ} \mathrm{C}$. The supernatants were collected, and the protein concentration was determined by BCA protein assay kit. The samples were mixed with $4 \times$ NuPAGE LDS loading buffer, separated on NuPAGE 4-12\% Bis-Tris gels, and subsequently transferred to PVDF membranes by a wet transfer apparatus (Bio-Rad, Hercules, USA). Following blocking with superblock at room temperature for $2 \mathrm{~h}$, the membranes were incubated with rabbit anti- $\beta$-actin $(1: 1000)$, anti-Smad2/3 (1:1000), anti-pSmad2/3 (1:1000), anti-CREB (1:1000), anti-p-CREB (1:1000), anti-ERK (1:1000), anti-p-ERK

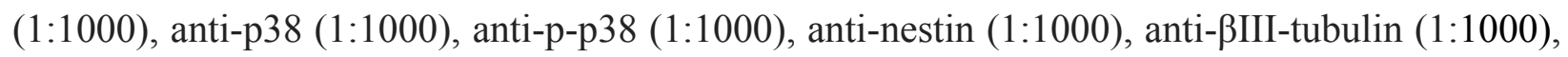
anti-GFAP (1:1000) and anti-GAPDH (1:1000), respectively, at $4^{\circ} \mathrm{C}$ overnight. After washing with PBST (PBS supplemented with $0.1 \%$ Tween 20), membranes were incubated with horseradish peroxidase-conjugated goat anti-rabbit $\operatorname{IgG}(1: 3000)$ at room temperature for $2 \mathrm{~h}$, and were visualized by ECL reagents. The ImageJ software was used for densitometric analyses of the blots.

\subsection{Bioinformatic analyses}

To further understand the functions and features of the identified and quantified proteins, we annotated functions and features of proteins from several different categories, including subcellular localization, domain, Gene Ontology (GO) and pathway.

WoLF PSORT (a subcellular localization predication tool, version of PSORT/PSORT II) and SubLoc ( http://www.bioinfo.tsinghua.edu.cn/SubLoc/ ) were used to predict subcellular localization of all identified differentially expressed proteins.

The domain functional description of the differentially expressed proteins were annotated by InterProScan (a sequence analysis application) based on protein sequence alignment method, and the InterPro domain database was used (http://www.ebi.ac.uk/interpro/).

GO annotation was derived from the UniProt-GOA database (http://www.ebi.ac.uk/GOA/), and the differentially expressed proteins were classified by GO annotation based on the three categories (GO term level 1): biological process, cellular component and molecular function. According to GO annotation information of the identified proteins, we summed up the amount of the differentially expressed proteins in each GO term of level 2.

The protein-protein interaction networks and pathways were annotated by Kyoto Encyclopedia of Genes and Genomes (KEGG) database.

\subsection{Statistical analysis}


255

256

257

258

259

260

261

262

263

264

265

266

267

268

269

270

271

272

273

274

275

276

277

278

279

280

281

282

283

284

285

286

287

288

289

The results were presented as the mean \pm standard error (SE). Multi-group comparisons were performed by one-way ANOVA followed by Tukey's post hoc test. Paired analysis of control and treatment was accomplished using two-tailed unpaired or unpaired Student's $t$-tests when appropriate. In addition, Statistical analyses were conducted using SPSS statistics software,version 17.0 (SPSS Inc., Chicago, USA), and $\mathrm{p}<0.05$ was considered statistically significant..

\section{Results}

\subsection{The positive and negative effects of GDF11 on cellular viability and}

\section{proliferation}

When compared with the counts of C17.2 cells initially seeded, both GDF11- and vehicletreated cells significantly proliferated after $72 \mathrm{~h}$ of cultivation (Supplementary Fig. S1). Imaging revealed that GDF11 significantly altered the morphology of C17.2 cells (Fig.1a). Cells without GDF11 treatment remained their native neural stem cell state (Fig. 1a, control), whereas cells treated with various concentrations of GDF11 showed visual outgrowth of neuritis, displaying phenotypes similar to neuron- and astrocyte-like cells (Fig.1a, GDF11). Remarkably, compared to the control, supplement with high concentrations of GDF11 (50 and $100 \mathrm{ng} / \mathrm{mL}$ ) significantly resulted in morphological changes (differentiation and apoptosis) (Supplementary Fig.S1a).

To investigate the effect of GDF11 on cell viability, C17.2 cells were treated with indicated concentrations of GDF11 $(0,12.5,25,50$ and $100 \mathrm{ng} / \mathrm{mL})$ for a $72 \mathrm{~h}$ period, followed by CCK-8 assays. GDF11 slightly increased (less than $10 \%, \mathrm{p}<0.05$ ) cell viability after $24 \mathrm{~h}$ treatment, whereas it did not affect the cell viability after $72 \mathrm{~h}$ treatment (Fig.1c).

As displayed in Fig.1d, all groups of C17.2 cells showed robust proliferation for the 6-passage duration. GDF11 showed no effect on C17.2 cell proliferation till the $4^{\text {th }}$ passages. From the $5^{\text {th }}$ passage, the low concentrations of GDF11 (12.5 and $25 \mathrm{ng} / \mathrm{mL})$ still didn't affect the proliferation of C17.2 cells, whereas higher concentrations of GDF11 (50 and $100 \mathrm{ng} / \mathrm{mL}$ ) significantly inhibited cell proliferation $(\mathrm{p}<0.05)$ and the exposure of $\mathrm{C} 17.2$ cells to $100 \mathrm{ng} / \mathrm{mL}$ GDF11 resulted in the lowest cumulative population doubling level during the 6 passages of cultivation amongst the 5 groups, which was approximately $17 \%$ lower than control $(\mathrm{p}<0.05)$.

Next, we detected the mRNA expression of cyclin D1 and cyclin D2, the cell cycle-related proteins. GDF11 slightly but not significantly attenuated the expression of cyclin D1 and cyclin D2 in the mRNA levels (Fig. $2 \mathrm{~d} ; \mathrm{p}>0.05$ ). These provide a potential molecular basis for the effects of GDF11 on C17.2 cell viability and proliferation.

Together, these results revealed that GDF11 slightly increased cell viability after a short-term (24h) cultivation and showed no effect on cell viability from $1^{\text {st }}$ to $4^{\text {th }}$ passage of cultivation (approximately 10 days), whereas high concentrations of GDF11 significantly suppressed 
290

291

292

293

294

295

296

297

298

299

300

301

302

303

304

305

306

307

308

309

310

311

312

313

314

315

316

317

318

319

320

321

322

323

324

cumulative population doubling for a long-term treatment.

\subsection{GDF11 induced differentiation and apoptosis of C17.2 cells}

The mRNA levels of the neural progenitor cell marker, nestin, were noticeably decreased after being treated with GDF11, as compared to control levels (Fig. 2a; $\mathrm{p}<0.01$ ). By contrast, the GDF11-treated groups showed significant increase in BIII-tubulin (neuronal biomarker) and GFAP (astrocytic biomarker) mRNA expression as compared to the control (Fig. 2a; $\mathrm{p}<0.05$ ). These all indicated the maturation and differentiation of C17.2 neural stem cells. The differences in nestin mRNA expression among the groups of GDF11 treatment were, however, not significant, similar to $\beta I I I-t u b u l i n$ and GFAP. Concomitantly with the mRNA expression, the protein levels of nestin, $\beta I I I-$ tubulin and GFAP confirmed the similar results by western blot (Fig. $2 \mathrm{~b}$ and $\mathrm{c}$ ). When compared with the control, GDF11-treated cells showed the protein level of nestin was significantly attenuated whereas $\beta$ III-tubulin and GFAP were up-regulated (Fig. $2 b$ and c), further indicating that GDF11 induced neuronal and astrocytic differentiation. However, no dose-dependent effect of GFD11 was observed.

The results of Annexin V-FITC/PI dual staining revealed that GDF11 substantially induced apoptosis of C17.2 cells. As shown in Fig. $1 \mathrm{~b}$ and e, the number of total (both early and late) apoptotic cells significantly increased in a GDF11 dose-dependent manner. After $72 \mathrm{~h}$ of cultivation, the apoptotic cells were negligible in C17.2 cells without GDF11-treated, whereas there were $2.1 \%, 9.8 \%, 13.1 \%$ and $17.7 \%$ of cells exhibiting apoptosis as a result of exposure to $12.5,25,50$ and $100 \mathrm{ng} / \mathrm{mL}$ GDF11, respectively $(\mathrm{p}<0.05)$. Meanwhile, the amount of necrotic cells showed a slight but significant increase when treated with GDF11.

\subsection{GDF11 suppressed the migration of $\mathrm{C} 17.2$ cells}

The migration of $\mathrm{C} 17.2$ cells was performed by a "scratch wound healing" assay. The wound closure data are shown in Fig.3. It was observed that the wound closure increased as cell migration progressed over time. After $12 \mathrm{~h}$, the wound area had little difference compared to the initial scratch area. As compared with that of $0 \mathrm{~h}$, wound area of $36 \mathrm{~h}$ significantly decreased, displaying 25.1\% (0 ng/mL GDF11), 64.9\% (12.5 ng/mL GDF11), 60.4\% (25 ng/mL GDF11), $70.9 \%$ (50 ng/mL GDF11) and 75.7\% (100 ng/mL GDF11) wound area, respectively (Fig.3b). These implied wound closure was significantly inhibited when cells were treated with GDF11. Of note, it was revealed that GDF11 showed slight but significant dose-dependent effects in the inhibition of the migration. Together, these results demonstrated that GDF11 significantly suppressed (but not completely abolished) the migratory potential of C17.2 neural stem cells.

\subsection{GDF11 activated phosphorylation levels of selected signaling kinases}

We deduced that, in C17.2 cells, GDF11 transmitted signals through phosphorylation of Smads, as GDF11 belongs to TGF- $\beta$ superfamily. First of all, we analyzed the effects of GDF11 
325

326

327

328

329

330

331

332

333

334

335

336

337

338

339

340

341

342

343

344

345

346

347

348

349

350

351

352

353

354

355

356

357

358

359

360

361

362

on TGF- $\beta$ signal pathway (the classical pathway activated by TGF- $\beta$ family members) in C17.2 neural stem cells. GDF11 showed no effect on both the mRNA and protein levels of Smad3 (Fig.2e and Fig.4a). For Smad2, GDF11 significantly up-regulated the transcriptional level other than the protein level (Fig.2e and Fig.4a). As shown in Fig.4a, cells untreated with GDF11 (control) displayed negligible phosphorylation of Smad2/3. On the contrary, presence of GDF11 pronouncedly phosphorylated Smad2/3 $(\mathrm{p}<0.05)$. However, no dose-dependent effect of GDF11 on Smad2/3 phosphorylation was observed. Moreover, we investigated the mRNA levels of receptors of TGF- $\beta$ superfamily, activin type IIB receptor (ActRIIB) and the type I receptors, activin receptor-like kinase 5 (ALK5). The results of qRT-PCR revealed that GDF11 didn't alter mRNA expression of ActRIIB and ALK (Fig.2e).

In order to further research the signal pathways affected by GDF11, we compared the phosphorylation levels of MAPKs in C17.2 cells treated with vehicle or GDF11 using a phospho-MAPK array kit. The fold changes were calculated from the ratio of intensity of the MAPK array from the GDF11 treated C17.2 cells to the control (untreated cells). Cut-off values were set 1.5-fold for up-regulated expression and 0.67-fold for down-regulated expression of a protein. We observed significant increases in the phosphorylation levels of several proteins in GDF11-treated cells compared with the untreated cells (Fig.5, Supplementary Table S2 and Supplementary Fig.S2). Overall, 50\% (13/26) proteins showed significantly increased phosphorylation after treatment with GDF11, whereas the phosphorylation levels of the remaining 50\% (13/26) proteins were still unchanged. Strikingly, when treated with GDF11, there were no proteins that showed decreased phosphorylation. In addition, the differentially expressed proteins that showed the most significant increases included Creb (3.42 times increased), HSP27 (3.05 fold increased), Akt1/2/3 (2.55-, 2.47- and 1.50-fold increased expression, respectively), GSK-3 $\beta$ and GSK $3 \alpha / \beta$ (2.12- and1.50 -fold increased, respectively), p38 $\alpha / \beta$ (3.21 and 1.73 times increased), Erk1 (1.57), MKK3/6 (2.03- and 1.52- fold increased, respectively) and p70s6k (1.93 times increased) (Fig.5c and Supplementary Fig.S2; p<0.05). These indicated that GDF11 activated the MAPK/Erk and p38 MAPK pathways but not JNK pathway in C17.2 neural stem cells. Remarkably, many of these differentially expressed proteins are involved in signal transductions of cell survival and apoptosis.

\subsection{Functional Classification of Differentially Expressed Proteins}

As shown in Table 1, the differentially expressed proteins were mainly classified as cytoplasmic $(n=8)$, nuclear $(n=7)$ and mitochondrial $(n=1)$ proteins.

For an overview of the differentially expressed proteins, GO annotation was carried out to identify the significantly enriched GO functions. According to the analysis, the 15 differentially expressed proteins between GDF11-treated cells and control were mainly clustered into 38 functional groups, including 18 biological processes, 12 cellular components, and 8 molecular functions (Fig.6a).

Biological process category according to GO annotations indicated that all the 15 differentially 
363

364

365

366

367

368

369

370

371

372

373

374

375

376

377

378

379

380

381

382

383

384

385

386

387

388

389

390

391

392

393

394

395

396

397

398

399

400

expressed proteins were involved in metabolic process. And other significant function groups included cellular process (13/15), response to stimulus (13/15), signaling (13/15) and localization (12/15), etc (Fig.6a).

In the category of cellular components, the differentially expressed proteins were mainly involved in cell (13/15), organelle (14/15), cytoplasm (12/15) and nucleus (13/15), indicating the similar subcellular localization that was obtained from WoLF PSORT (Table 1). Not only the similarities but also differences were found between the cellular component category and subcellular localization results. According to the functional analysis of GO annotation, we found six proteins were involved in plasma membrane, however, no membrane-associated proteins were observed from subcellular localization results.

The most representative molecular function category was "binding", which accounted for all the 15 differentially expressed proteins, and most of the differentially expressed proteins were also involved in catalytic activity (11/15), transferase activity (11/15) and kinase activity (11/15). These results also elucidated that the related signal pathways activated by GDF11.

\subsection{KEGG Enriched Pathways}

To explore the potential mechanisms for GDF11-mediated cell behavior (cellular proliferation, differentiation, apoptosis and migration) in C17.2 neural stem cells, we used the KEGG database to determine the protein-protein interaction networks and pathways involved in the up-regulated phosphoproteins. The 15 differentially expressed proteins were mainly mapped to 51 pathways according to the KEGG database, which were mainly associated with environmental information processing (signal transduction), organismal systems (immune system, nervous system, endocrine system and ageing), cellular processes (cell growth and death, transport and catabolism, and cellular community) and human diseases (drug resistance, endocrine and metabolic diseases, neurodegenerative diseases, infectious diseases, and cancers) (Supplementary Table S3). These all indicated the differentially expressed proteins were mainly involved in signal transduction of cellular behavior. Furthermore, domain functional description of the differentially expressed proteins annotated by InterProScan, were significantly enriched in protein kinase domain (25.58\%) and protein kinase-like domain (25.58\%) (Fig.6b). These were also in line with the results of molecular function category of GO annotation which indicated the differentially expressed proteins were mainly in connection with catalytic activity, transferase activity and kinase activity (Fig. 6a).

A major overlapping network was enriched in this analysis (Fig.6c). Three canonical signaling pathways (TGF- $\beta$, PI3K-Akt and MAPK signaling pathways), that were activated by the upregulation of phosphoproteins, were identified, and the cross-talking signaling cascade was shown as well. One mainly functional cluster was apparent in the protein-protein interaction, including Akt1/2/3 (the key components in the PI3K-Akt signal pathway), Erk1 (the key components of MAPK/Erk pathway) and p38 $\alpha / \beta$ (the key components in the p38 MAPK signal pathway). These results provided a possible resource for future studies of the proteins involved 
401

402

403

404

405

406

407

408

409

410

411

412

413

414

415

416

417

418

419

420

421

422

423

424

425

426

427

428

429

430

431

432

433

434

435

436

437

in GDF11-treated C17.2 cells.

\subsection{Validation of selected differentially expressed proteins}

To confirm the results of phospho-MAPK array, three differentially expressed protein candidates (Creb, p38 and Erk) were selected for further validation using western blot. Total protein lysates from $\mathrm{C} 17.2$ cells cultured with indicated concentrations of GDF11 $(0,12.5,25,50$ and $100 \mathrm{ng} / \mathrm{ml}$, respectively) were prepared and the phosphorylation levels were determined by their respective phosphorylated antibodies. When compared with control, no detectable changes in total Creb, p38 or Erk protein expression were observed in GDF11-treated C17.2 cells. Nevertheless, GDF11-treatment significantly increased the phosphorylation levels of Creb, p38 and Erk (Fig.4b, c and d; all p <0.05). These western blot results were generally consistent with the results of the phospho-MAPK array.

\section{Discussion}

Around the world, the number of aged people is precipitously increasing. Therefore, searching for anti-ageing or rejuvenating factors is quite important to develop therapeutic strategies for the treatment of age-related diseases. Recently, GDF11 was suggested as a potential rejuvenating factor, which not only reversed age-related cardiac hypertrophy and dysfunction in skeletal muscle in mouse (Loffredo et al. 2013; Poggioli et al. 2016; Sinha et al. 2014), but also induced rejuvenation of impairments in cognitive function of ageing mouse by remodeling the cerebral vascular and enhancing neurogenesis (Katsimpardi et al. 2014). Recently, a prospective cohort study also revealed that higher levels of GDF11/8 were associated with lower risk of cardiovascular events and death in patients with stable ischaemic heart disease (Olson et al. 2015). However, these initial findings have been challenged by later recent studies. It was reported that GDF11 inhibited muscle regeneration and decreased satellite cell expansion in mice (Egerman et.al. 2015). Hinken et al. (2016) also suggested GDF11 wasn't a rejuvenator for aged murine skeletal muscle satellite cells. In addition, restoring GDF11 in old mice showed no effect on pathological hypertrophy (Smith et al. 2015).

Because GDF11 was reported to improve neurogenic rejuvenation, we hypothesized that GDF11 influenced the cellular behavior of C17.2 neural stem cells, including viability, proliferation, differentiation, apoptosis and migration. Therefore, we focused on the effects and potential mechanism of action of GDF11 on viability, proliferation, differentiation, apoptosis and migration in C17.2 cells. Here, our results indicated that GDF11 substantially induced differentiation and apoptosis, and suppressed migration of C17.2 cells mainly through MAPK signal pathway. Meanwhile, GDF11 induced sight but significant increases in cellular viability in a short time of growth $(24 \mathrm{~h})$ and showed no effects on cellular viability for medium-term cultivation ( $<4$ passages; approximately 10 days). For long-term cultivation ( $>4$ passages), high concentrations of GDF11 significantly inhibited the proliferation of C17.2 cells (Fig. 1c and d; $\mathrm{p}<0.05$ ). To the best of our knowledge, we are unaware of any similar published results. 
438

439

440

441

442

443

444

445

446

447

448

449

450

451

452

453

454

455

456

457

458

459

460

461

462

463

464

465

466

467

468

469

470

471

472

473

474

475

476

477

Strikingly, similar to our results, it was found that GDF11 slightly increased cell viability after short-term treatment and slightly decreased cell viability after long-term treatment in human umbilical vein endothelial cells (Zhang et al. 2016). Previously, it was suggested that GDF11 acted as a negative regulator of neurogenesis (Wu et al. 2003). Recently, Williams et al. (2013) reported a controversial finding that GDF11 suppressed proliferation and migration of Cor-1 cells, whereas no effect on differentiation was observed. The conflicting results may be caused by GDF11 from different vendors, different batches of GDF11 from the same manufacturer, or cells from different sources.

As a member of TGF- $\beta$ superfamily, it was reported that GDF11 activated TGF- $\beta$ signal pathway as a consequence of phosphorylating Smad2/3 in several cell types (Liu et al. 2016; Loffredo et al. 2013; Zhang et al. 2016). In the present study, we successfully observed GDF11 phosphorylated Smad2/3 in C17.2 neural stem cells. Consistent with our results, it was also confirmed that Cor-1 neural stem cell line was able to respond to GDF11 stimulation by Smad2/3 phosphorylation (Williams et al. 2013). It is widely known that the Smad2/3-dependent TGF- $\beta$ signals have been implicated in the proliferation and differentiation of neural stem cell. For example, GDF11 negatively regulated self-renewal of neuroepithelial stem cells through TGF- $\beta$ signals (Falk et al. 2008).

Proteins, not genes, are the specific practitioners of cellular life organisms. Although genome and transcriptome analyses are very useful to reveal the mechanism of GDF11 stimulation, proteomic profiles may not be accurately predicted by transcriptome profiling due to several factors, such as post-translational modifications. Therefore, research on proteomics is helpful to provide new information concerning the C17.2 cells response to GDF11 stimulation. Based on phospho-proteome profiling array and bioinformatic analysis (Figs.5 and 6), we found 15 differentially expressed proteins, including p38, Erk, Akt, GSK3 $\alpha / \beta$, Creb, MKK3/6, p70S6k and HSP27, which were mainly involved in signal transductions of cell survival and apoptosis. Besides TGF- $\beta$ signal pathway, we also found Akt pathway and two important MAPK pathways (Erk MAPK and p38 MAPK pathways) were activated, but not JNK pathway. Similarly, it also reported that GDF11 activated TGF- $\beta / \mathrm{Smad} 2 / 3$ but suppressed JNK signaling pathways in apolipoprotein E-null mice (Mei et al. 2016). The functions of Erk MAPK and p38 MAPK pathways are complex, which are involved in controlling cell proliferation, differentiation, survival/apoptosis and migration (Wagner \& Nebreda 2009). Various studies demonstrated Erk MAPK pathway was involved in cellular proliferation and migration (Khodosevich 2009; Wu et al. 2014). Although p38 MAPK pathway is normally associated with anti-proliferative and apoptotic functions (Wagner \& Nebreda 2009), it was also reported that p38 was implicated in pro-survival functions, including positively regulating proliferation, differentiation and antiapoptosis (Halawani et al. 2004; Ricote et al. 2006; Terriente-Félix et al. 2017; Thornton et al. 2008). MAPK/Erk, Akt and p38 MAPK pathways were required for the migration of cortical neurons upon HGF stimulation (Segarra et al. 2006), however, we observed GDF11 significantly suppressed the migratory capacity of C17.2 neural stem cells with the activation of Erk MAPK, PI3K/Akt and p38 MAPK pathways. Of the 15 differentially expressed proteins we identified, 
478 HSP27 and p70S6K are two important downstream effectors of Akt pathway. 479 Mechanistically, PI3K/Akt phosphorylates HSP27 and p70S6K, which facilitate protein folding 480 and control protein synthesis, to inhibit apoptosis and promote proliferation (Khodosevich 2009; 481 Li et al. 2008; Rane et al. 2003). All of these suggested that GDF11 regulated the proliferation, 482 differentiation, apoptosis and migration of C17.2 cells by cross-talking with MAPK signaling 483 pathway.

484 Neuronal migration is a complex and key process in physiological and pathological conditions. 485 Increasing the quantity of nerve cells and the migration of neurons to the final position are 486 critical to reverse age-related dysfunction in brain (Contreras-Vallejos et al. 2012; Martino et al. 487 2011; Zhao et al. 2008). It should be noted that, although GDF11-treatment for 24h slightly 488 increased the viability of C17.2 cells (Fig.1c), it showed no effect on cell death (Fig. S1b). 489 GDF11 didn't change the cell viability after $72 \mathrm{~h}$ cultivation (Fig.1c), whereas it 490 significantly stimulated cell death (Fig.S1a). In addition, we found GDF11 significantly 491 suppressed the migration of C17.2 cells. Despite the fact that GDF11 indeed induced C17.2 cells 492 to differentiate into neurons and astrocytes, our point of view is that it should be cautious if 493 GDF11 is considered as a rejuvenated factor for neural stem cells.

494

495

\section{Conclusion}

In the present study, we found that GDF11 was an important regulator of neural stem cell. In C17.2 neural stem cells, GDF11 showed a positive effect on cell viability after $24 \mathrm{~h}$ treatment but displayed a tendency of a negative effect for long-term cultivation. In addition, GDF11 significantly induced differentiation and apoptosis, and suppressed migration of C17.2 neural stem cells. Further analysis of MAPK signaling pathway, which was activated by GDF11, preliminary illustrated the potential mechanism of action by which the cellular behavior was induced. Taken together our current findings implied that GDF11 might be a potential target for pharmacologic blockade instead of a rejuvenated factor for neural stem cells.

\section{Acknowledgements}

The authors are grateful for helpful comments of bioinformatic analyses from Jingjie PTM BioLab (Hangzhou) Co. Ltd (China).

\section{References}

Contreras-Vallejos E, Utreras E, and Gonzalez-Billault C. 2012. Going out of the brain: non-nervous system physiological and pathological functions of Cdk5. Cellular signalling 24:44-52.

Egerman Marc A, Cadena Samuel M, Gilbert Jason A, Meyer A, Nelson Hallie N, Swalley Susanne E, Mallozzi C, Jacobi C, Jennings Lori L, Clay I, Laurent G, Ma S, Brachat S, Lach-Trifilieff E, Shavlakadze T, Trendelenburg A-U, Brack Andrew S, and Glass David J. 2015. GDF11 Increases with Age and Inhibits Skeletal Muscle 
512

513

514

515

516

517

518

519

520

521

522

523

524

525

526

527

528

529

530

531

532

533

534

535

536

537

538

539

540

541

542

543

544

545

546

547

548

549

550

551

552

Regeneration. Cell Metabolism 22:164-174. 10.1016/j.cmet.2015.05.010

Falk S, Wurdak H, Ittner LM, Ille F, Sumara G, Schmid M-T, Draganova K, Lang KS, Paratore C, and Leveen P. 2008. Brain area-specific effect of TGF- $\beta$ signaling on Wnt-dependent neural stem cell expansion. Cell stem cell 2:472-483.

Halawani D, Mondeh R, Stanton L-A, and Beier F. 2004. p38 MAP kinase signaling is necessary for rat chondrosarcoma cell proliferation. Oncogene 23:3726-3731. 10.1038/sj.onc.1207422

Hinken AC, Powers JM, Luo G, Holt JA, Billin AN, and Russell AJ. 2016. Lack of evidence for GDF11 as a rejuvenator of aged skeletal muscle satellite cells. Aging cell 15:582-584.

Katsimpardi L, Litterman NK, Schein PA, Miller CM, Loffredo FS, Wojtkiewicz GR, Chen JW, Lee RT, Wagers AJ, and Rubin LL. 2014. Vascular and Neurogenic Rejuvenation of the Aging Mouse Brain by Young Systemic Factors. Science 344:630-634. 10.1126/science.1251141

Khodosevich K. 2009. Major signaling pathways in migrating neuroblasts. Frontiers in Molecular Neuroscience 2:7. 10.3389/neuro.02.007.2009

Li W, Tan D, Zhang Z, Liang JJ, and Brown RE. 2008. Activation of Akt-mTOR-p70S6K pathway in angiogenesis in hepatocellular carcinoma. Oncology reports 20:713-719.

Liu W, Zhou L, Zhou C, Zhang S, Jing J, Xie L, Sun N, Duan X, Jing W, Liang X, Zhao H, Ye L, Chen Q, and Yuan Q. 2016. GDF11 decreases bone mass by stimulating osteoclastogenesis and inhibiting osteoblast differentiation. Nature Communications 7:12794. 10.1038/ncomms12794

Loffredo FS, Steinhauser ML, Jay SM, Gannon J, Pancoast JR, Yalamanchi P, Sinha M, Dall'Osso C, Khong D, Shadrach JL, Miller CM, Singer BS, Stewart A, Psychogios N, Gerszten RE, Hartigan AJ, Kim M-J, Serwold T, Wagers AJ, and Lee RT. 2013. Growth Differentiation Factor 11 Is a Circulating Factor that Reverses AgeRelated Cardiac Hypertrophy. Cell 153:828-839. 10.1016/j.cell.2013.04.015

Martino G, Pluchino S, Bonfanti L, and Schwartz M. 2011. Brain regeneration in physiology and pathology: the immune signature driving therapeutic plasticity of neural stem cells. Physiological reviews 91:1281-1304.

Mei W, Xiang G, Li Y, Li H, Xiang L, Lu J, Xiang L, Dong J, and Liu M. 2016. GDF11 protects against endothelial injury and reduces atherosclerotic lesion formation in apolipoprotein E-null mice. Molecular Therapy 24:19261938.

Oh SP, Yeo C-Y, Lee Y, Schrewe H, Whitman M, and Li E. 2002. Activin type IIA and IIB receptors mediate Gdf11 signaling in axial vertebral patterning. Genes \& development 16:2749-2754.

Olson KA, Beatty AL, Heidecker B, Regan MC, Brody EN, Foreman T, Kato S, Mehler RE, Singer BS, and Hveem K. 2015. Editor's choice: Association of growth differentiation factor 11/8, putative anti-ageing factor, with cardiovascular outcomes and overall mortality in humans: analysis of the Heart and Soul and HUNT3 cohorts. European Heart Journal 36:3426.

Pepinsky B, Gong B-J, Gao Y, Lehmann A, Ferrant J, Amatucci J, Sun Y, Bush M, Walz T, Pederson N, Cameron T, and Wen D. 2017. A Prodomain Fragment from the Proteolytic Activation of Growth Differentiation Factor 11 Remains Associated with the Mature Growth Factor and Keeps It Soluble. Biochemistry 56:4405-4418. 10.1021/acs.biochem.7b00302

Poggioli T, Vujic A, Yang P, Macias-Trevino C, Uygur A, Loffredo FS, Pancoast JR, Cho M, Goldstein J, Tandias RM, Gonzalez E, Walker RG, Thompson TB, Wagers AJ, Fong YW, and Lee RT. 2016. Circulating Growth Differentiation Factor 11/8 Levels Decline With AgeNovelty and Significance. Circulation Research 118:2937. 10.1161 /circresaha.115.307521 
553

554

555

556

557

558

559

560

561

562

563

564

565

566

567

568

569

570

571

572

573

574

575

576

577

578

579

580

581

582

583

584

585

586

587

588

589

590

591

592

593

Rane MJ, Pan Y, Singh S, Powell DW, Wu R, Cummins T, Chen Q, McLeish KR, and Klein JB. 2003. Heat Shock Protein 27 Controls Apoptosis by Regulating Akt Activation. Journal of Biological Chemistry 278:27828-27835. 10.1074/jbc.M303417200

Ricote M, García-Tuñón I, Bethencourt F, Fraile B, Onsurbe P, Paniagua R, and Royuela M. 2006. The p38 transduction pathway in prostatic neoplasia. The Journal of Pathology 208:401-407. 10.1002/path.1910

Santos R, Wu J, Hamilton JA, Pinter R, Hindges R, and Calof AL. 2012. Restoration of Retinal Development in Vsx2 Deficient Mice by Reduction of Gdf11 Levels. Advances in experimental medicine and biology 723:671-677.

Segarra J, Balenci L, Drenth T, Maina F, and Lamballe F. 2006. Combined Signaling through ERK, PI3K/AKT, and RAC1/p38 Is Required for Met-triggered Cortical Neuron Migration. Journal of Biological Chemistry 281:4771-4778. 10.1074/jbc.M508298200

Sinha M, Jang YC, Oh J, Khong D, Wu EY, Manohar R, Miller C, Regalado SG, Loffredo FS, and Pancoast JR. 2014. Restoring systemic GDF11 levels reverses age-related dysfunction in mouse skeletal muscle. Science 344:649-652.

Smith SC, Zhang X, Zhang X, Gross P, Starosta T, Mohsin S, Franti M, Gupta P, Hayes D, Myzithras M, Kahn J, Tanner J, Weldon SM, Khalil A, Guo X, Sabri A, Chen X, MacDonnell S, and Houser SR. 2015. GDF11 Does Not Rescue Aging-Related Pathological HypertrophyNovelty and Significance. Circulation Research 117:926932. 10.1161/circresaha.115.307527

Terriente-Félix A, Pérez L, Bray SJ, Nebreda AR, and Milán M. 2017. A Drosophila model of myeloproliferative neoplasm reveals a feed-forward loop in the JAK pathway mediated by p38 MAPK signalling. Disease Models \& Mechanisms 10:399-407. 10.1242/dmm.028118

Thornton TM, Pedraza-Alva G, Deng B, Wood CD, Aronshtam A, Clements JL, Sabio G, Davis RJ, Matthews DE, Doble B, and Rincon M. 2008. Phosphorylation by p38 MAPK as an Alternative Pathway for GSK3 Inactivation. Science 320:667-670. 10.1126/science.1156037

Wagner EF, and Nebreda ÁR. 2009. Signal integration by JNK and p38 MAPK pathways in cancer development. Nature Reviews Cancer 9:537-549. 10.1038/nrc2694

Walker RG, Czepnik M, Goebel EJ, McCoy JC, Vujic A, Cho M, Oh J, Aykul S, Walton KL, Schang G, Bernard DJ, Hinck AP, Harrison CA, Martinez-Hackert E, Wagers AJ, Lee RT, and Thompson TB. 2017. Structural basis for potency differences between GDF8 and GDF11. BMC Biology 15:19. 10.1186/s12915-017-0350-1

Walker RG, Poggioli T, Katsimpardi L, Buchanan SM, Oh J, Wattrus S, Heidecker B, Fong YW, Rubin LL, Ganz P, Thompson TB, Wagers AJ, and Lee RT. 2016. Biochemistry and Biology of GDF11 and MyostatinResponse to Walker et al. Circulation Research 118:1125-1142. 10.1161/circresaha.116.308391

Williams G, Zentar MP, Gajendra S, Sonego M, Doherty P, and Lalli G. 2013. Transcriptional Basis for the Inhibition of Neural Stem Cell Proliferation and Migration by the TGFß-Family Member GDF11. PLoS ONE 8:e78478. 10.1371/journal.pone.0078478

Wu H-H, Ivkovic S, Murray RC, Jaramillo S, Lyons KM, Johnson JE, and Calof AL. 2003. Autoregulation of Neurogenesis by GDF11. Neuron 37:197.

Wu X-S, Wang X-A, Wu W-G, Hu Y-P, Li M-L, Ding Q, Weng H, Shu Y-J, Liu T-Y, Jiang L, Cao Y, Bao R-F, Mu J-S, Tan Z-J, Tao F, and Liu Y-B. 2014. MALAT1 promotes the proliferation and metastasis of gallbladder cancer cells by activating the ERK/MAPK pathway. Cancer Biology \& Therapy 15:806-814. 10.4161/cbt.28584

Zhang Y-H, Cheng F, Du X-T, Gao J-L, Xiao X-L, Li N, Li S-L, and Dong D-L. 2016. GDF11/BMP11 activates both

Peer] reviewing PDF | (2018:06:28991:2:0:NEW 25 Jul 2018) 
594 smad1/5/8 and smad2/3 signals but shows no significant effect on proliferation and migration of human 595 umbilical vein endothelial cells. Oncotarget 7:12063.

596 Zhao C, Deng W, and Gage FH. 2008. Mechanisms and functional implications of adult neurogenesis. Cell 132:645597660 .

598 


\section{Figure 1}

Effect of GDF11 on C17.2 cells.

(a) The representative images of live and dead cell staining. C17.2 cells were cultured with indicated concentrations of GDF11. Images were obtained at 200X magnification by inverted fluorescence microscope. The live cells were stained with calcein AM in green, and the dead cells were stained with EthD-1 in red. (b) GDF11 induced apoptosis in C17.2 neural stem cells. C17.2 cells were treated with vehicle or $\operatorname{GDF11}(12.5,25,50$ and $100 \mathrm{ng} / \mathrm{mL})$ for $48 \mathrm{~h}$ and cell distribution was analysed using Annexin V-FITC and PI dual staining. The FITC and PI fluorescence was measured by flow cytometer with FL-1 and FL-2 filters, respectively. Lower left quadrant-- live cells (Annexin $\mathrm{V}-/ \mathrm{PI}-$ ), lower right quadrant--early/primary apoptotic cells (Annexin $\mathrm{V}+/ \mathrm{PI}-$ ), upper right quadrant--late/secondary apoptotic cells (Annexin $\mathrm{V}+/ \mathrm{PI}+$ ) and upper left quadrant--necrotic cells (Annexin V-/PI+). (c) The viability of C17.2 cells after $24 \mathrm{~h}$ or $72 \mathrm{~h}$ of cultivation with various concentrations of GDF11 or vehicle was measured using CCK-8 method.. $N=3, p<0.05$. (d) Cumulative population doubling levels of C17.2 cells supplemented with different GDF11 concentrations for a total period of 6 passages. $N=4$, $* p<0.05$ compared with control. (e) Quantitative analyses of the GDF11 effect on apoptosis. $\mathrm{N}=3, * \mathrm{p}<0.05$ versus with vehicle control and ${ }^{*} \mathrm{p}<0.01$ versus with vehicle control. 

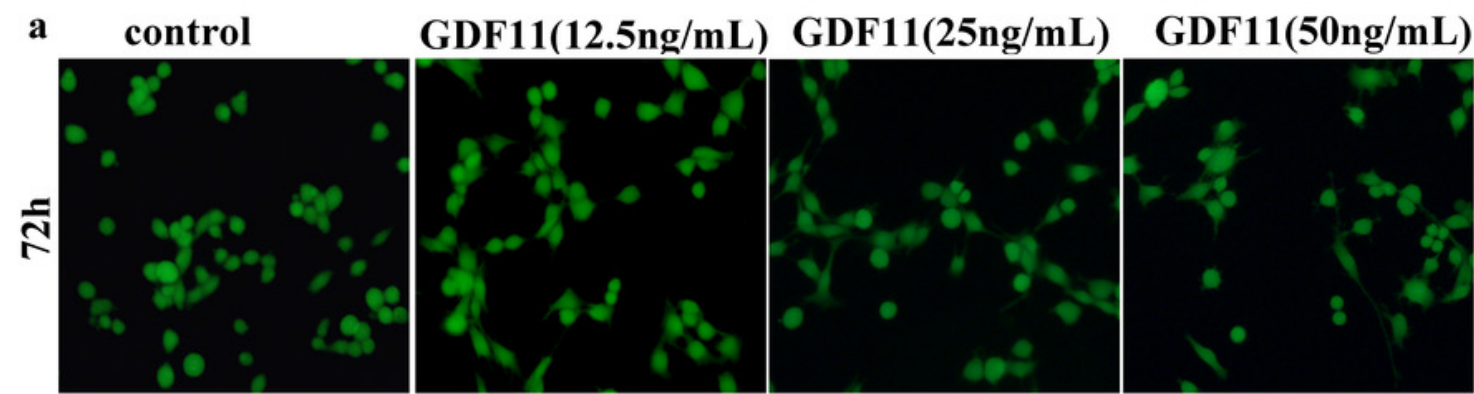

GDF11(100ng/mL)
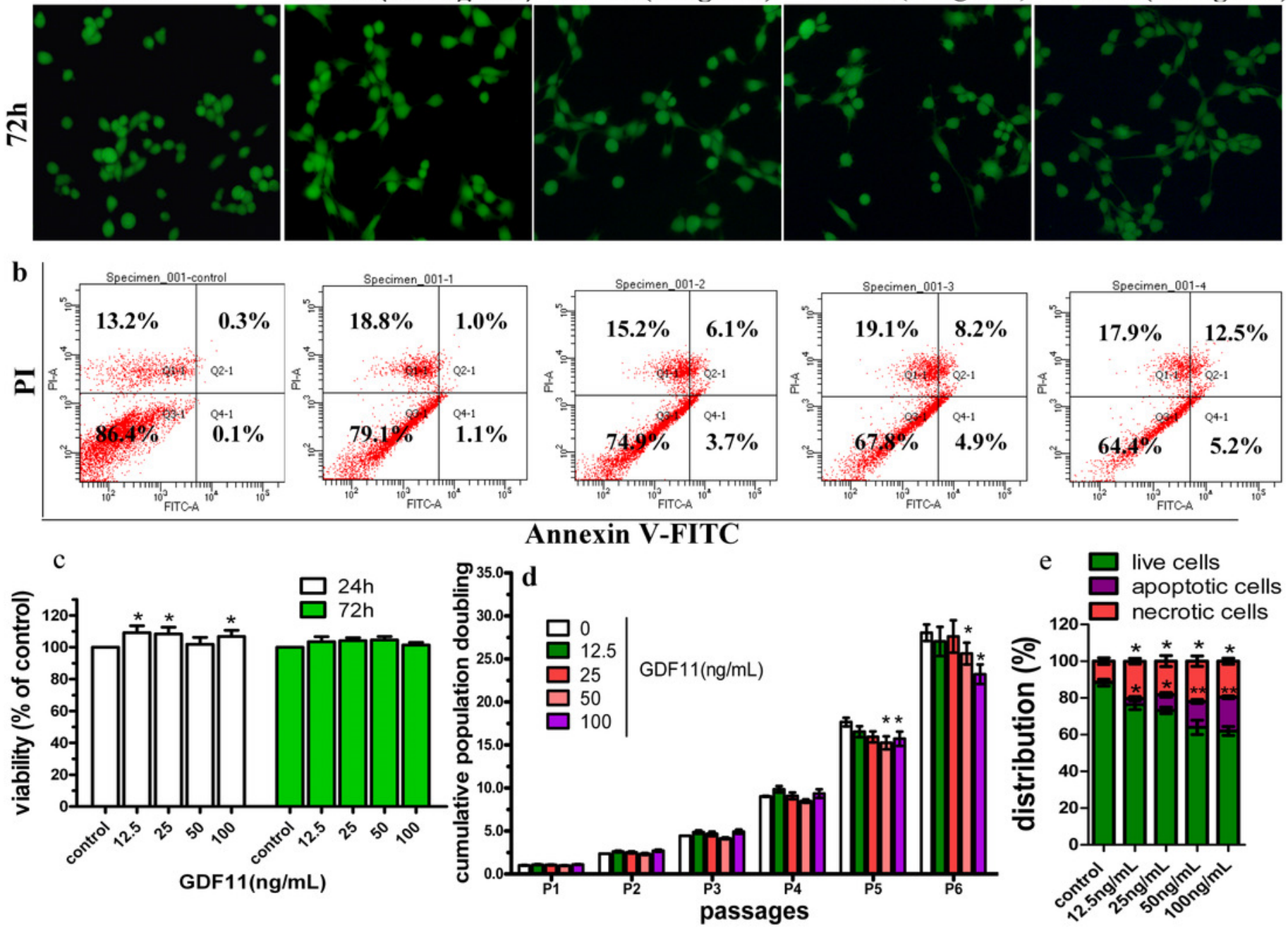


\section{Figure 2}

The effect of GDF11 on mRNA and protein expression

(a) Nestin, BIII-tubulin and GFAP mRNA levels of C17.2 cells after GDF11 or vehicle (control) treated for $5 \mathrm{~h}$. The results display mean $\pm S D$ of $n=4$ and were analysed by one-way ANOVA followed by Tukey's post hoc test. $* p<0.05$ as compared with mRNA levels in control cells. (b) Nestin, BIII-tubulin and GFAP protein levels of C17.2 cells after GDF11 (50ng/mL, "T") or vehicle (" $\mathrm{C}$ ") treated for $72 \mathrm{~h}$. (c) Quantitative analyses of protein expression in relation to $\beta$ actin expression. Results were analysed by Student's t-test. $N=6, * p<0.05$. (d) Cyclin D1, Cyclin D2 and EGFR mRNA expression after GDF11 or vehicle treated for $5 \mathrm{~h} . \mathrm{N}=5,{ }^{*} \mathrm{p}<0.05$ and ${ }^{* *} p<0.01$. (e) The mRNA levels of Smad2, Smad3, Alk5 and ActRIIB after GDF11 or vehicle treated for $5 \mathrm{~h} . \mathrm{N}=5, * \mathrm{p}<0.05$ and $* * \mathrm{p}<0.01$. 

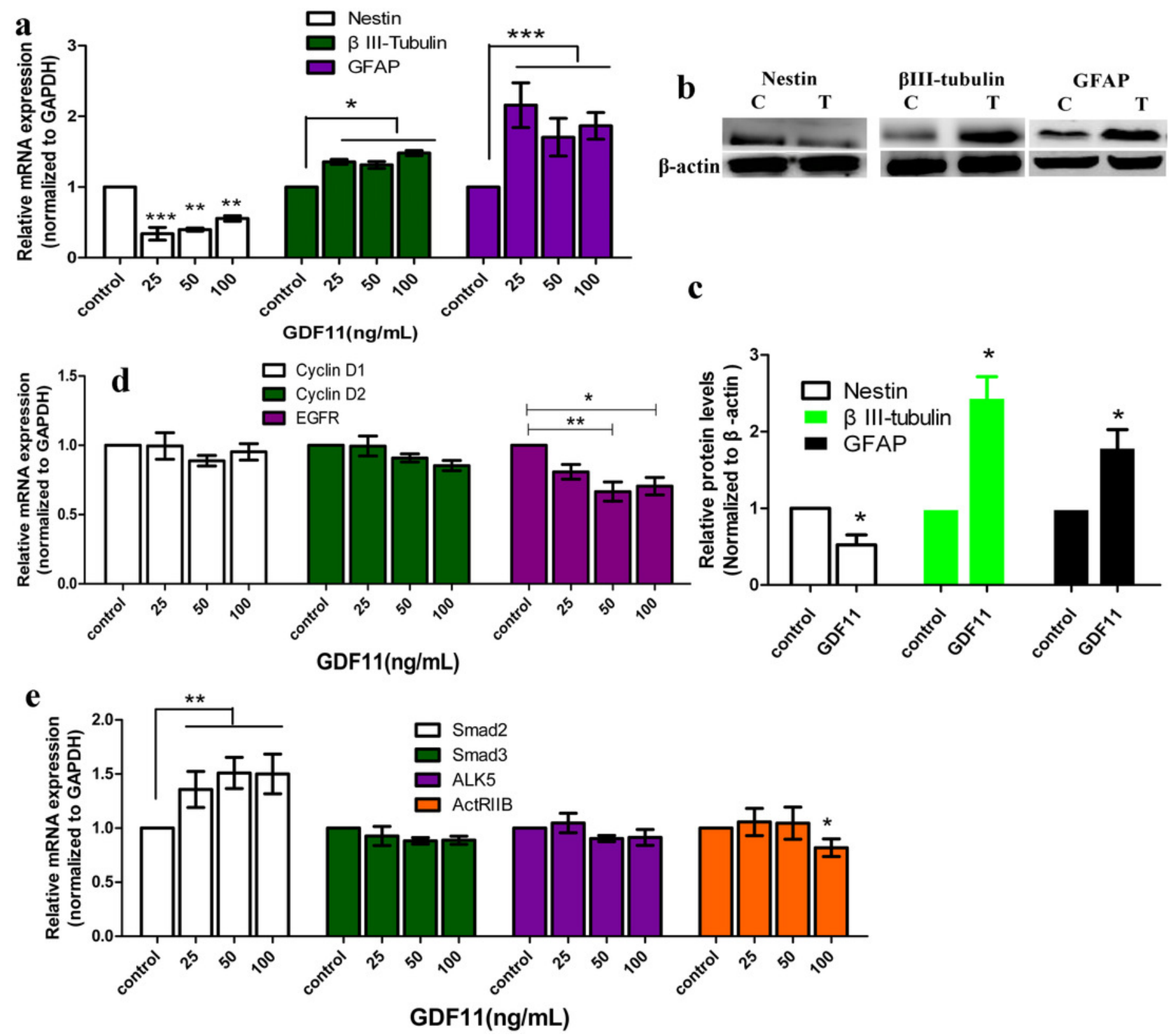


\section{Figure 3}

GDF11 inhibited the migration of C17.2 cells

Scratch-wound closure was monitored over time. (a) Representative images showed that GDF11 induced significantly decreased migration speed compared with control (GDF11 untreated cells). Black lines in each graph were pointed toward wound edges. (b) Quantification of the remaining wound area uncovered by migrating C17.2 cells revealed a significant inhibition of migration in GDF11-treated cells. The scratch wound areas at time point 0 hour were set to $100 \%$, and the wound areas at other time point were normalized to their respective 0 hours. Bar is $500 \mu m(n=5 ; * p<0.05)$. 


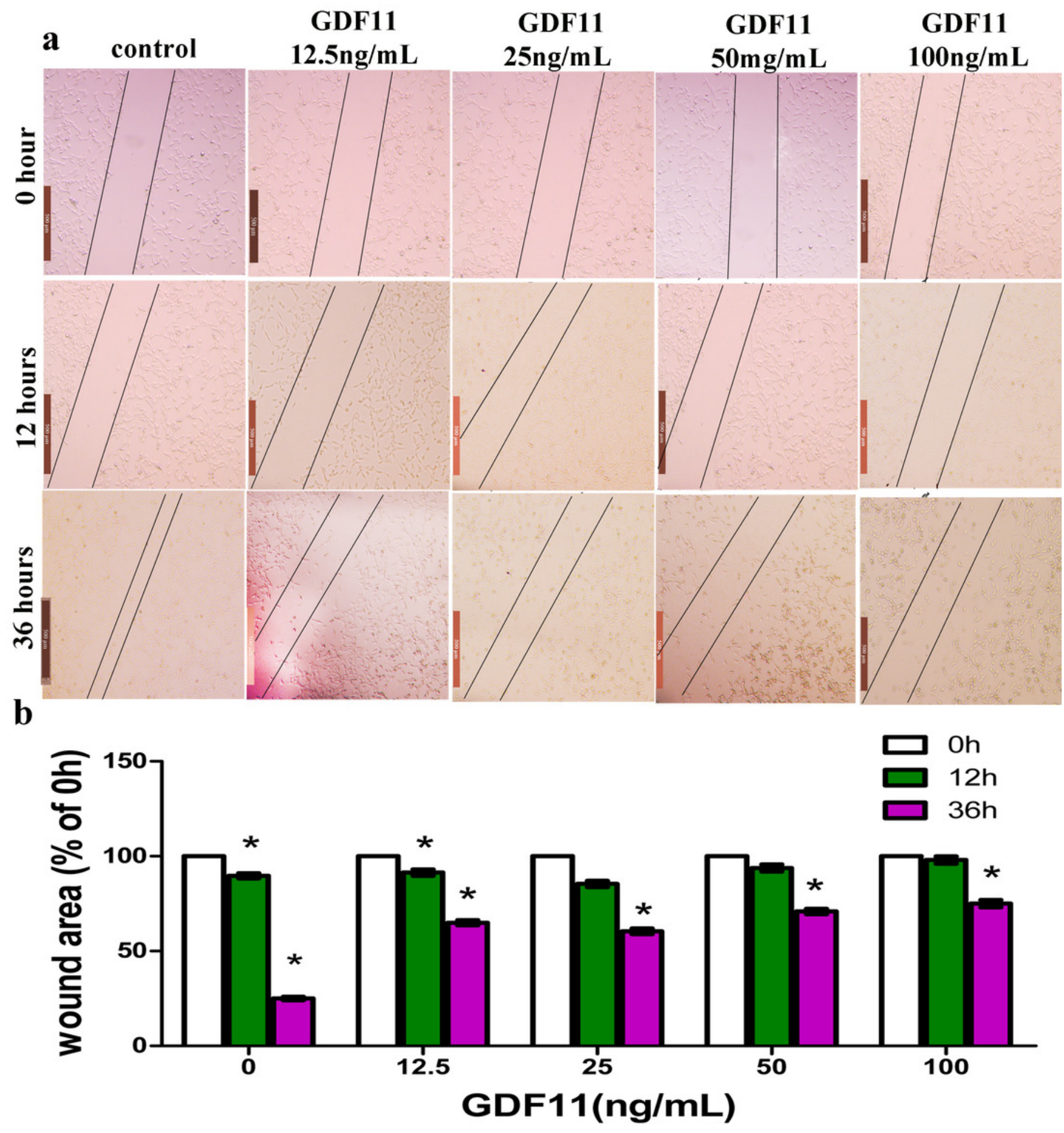




\section{Figure 4}

GDF11 increased the phosphorylations of Smad2/3, Creb, p38 and Erk in C17.2 neural stem cells.

(a-d). After 24h cultivation, GDF11 showed no effect on total protein of Smad2/3, Creb, p38 and Erk, but significantly phosphorylated Smad2 (Ser465/467), Smad3(Ser423/425), Creb(Ser133), p38( Thr180/Tyr182) and Erk (Thr202/Tyr204) in C17.2 cells. N=4, ${ }^{*} p<0.05$, $* * p<0.01$ and ${ }^{* * *} \mathrm{p}<0.001$ when compared with control. 
$\mathbf{a}$

$\mathrm{p}-\mathrm{Smad} 2$ p-Smad3

Smad2

Smad3

$\beta$-actin

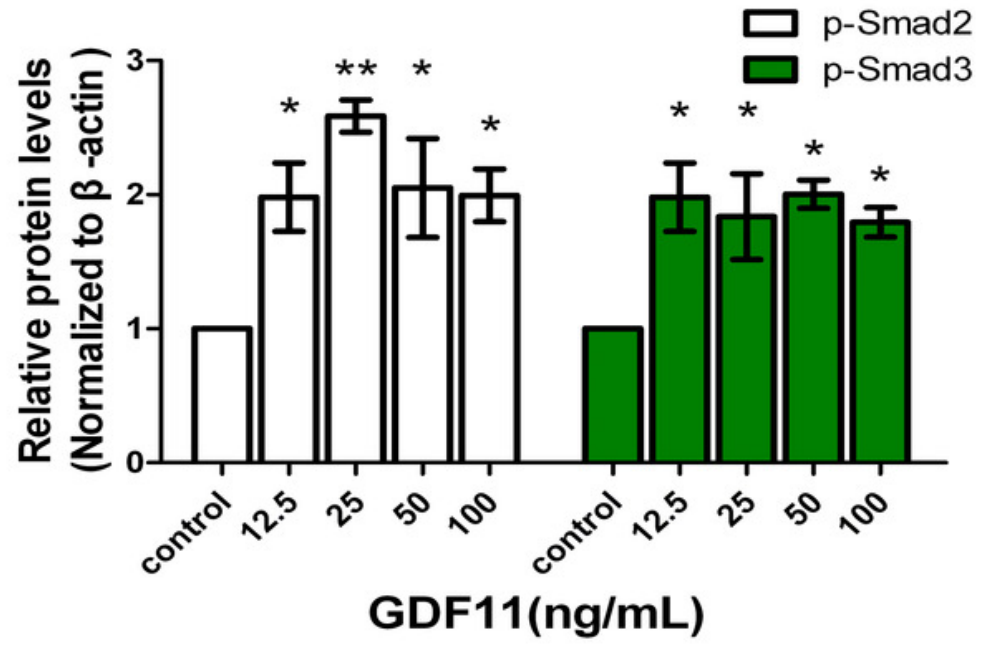

p-Creb

$$
\begin{array}{lllll}
\multicolumn{4}{c}{\text { GDF11 }(\mathrm{ng} / \mathrm{mL})} \\
\hline 0 & 12.5 & 25 & 50 & 100
\end{array}
$$

Creb

GAPDH

c

GDF11 (ng/mL) \begin{tabular}{lllll}
\hline 0 & 12.5 & 25 & 50 & 100
\end{tabular}

p-p38

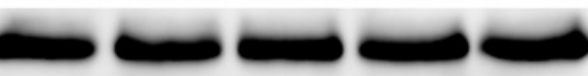

$\square$

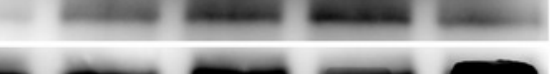
p38

GAPDH

d

$$
\begin{array}{lllll} 
& \multicolumn{4}{l}{\text { GDF11(ng/mL) }} \\
\hline 0 & 12.5 & \mathbf{2 5} & \mathbf{5 0} & \mathbf{1 0 0}
\end{array}
$$

p-Erk1/2

Erk1/2

GAPDH
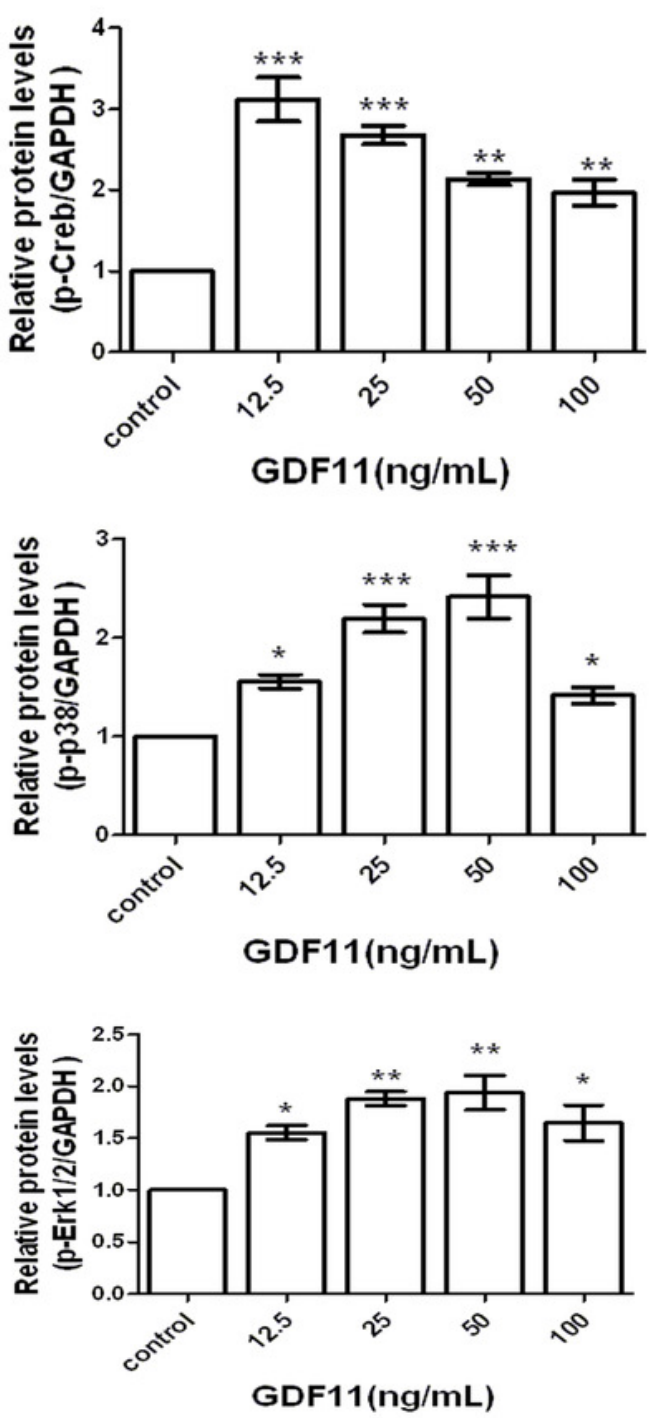


\section{Figure 5}

Alterations of MAPK pathway-related proteins in GDF11-treated C17.2 cells.

(a). Phosphoproteome profiling of C17.2 cells in response to GDF11 stimulation. Total cell lysates from C17.2 cells with25ng/mL GDF11- or vehicle-treated were incubated on membranes of the phospho-proteomics platforms (human Phospho-MAPK, 23 different MAPKs and other serine/threonine kinases), as described in "Materials and Methods". (b). Human Phospho-MAPK array coordinates. (c). The graph shows the relative fold change of proteins with significant difference upon GDF11 treatment, setting 1 for control. Protein levels with higher than \pm 1.5 folds indicated by dotted lines are considered as the differentially expressed proteins.

a

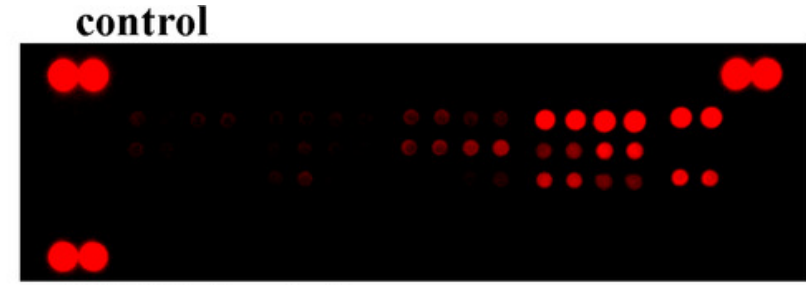

$$
\text { GFD11-treated }
$$

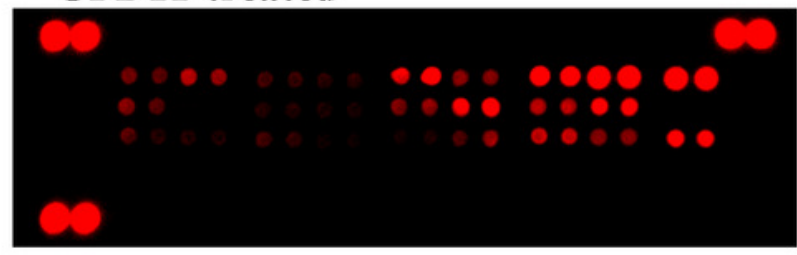

b

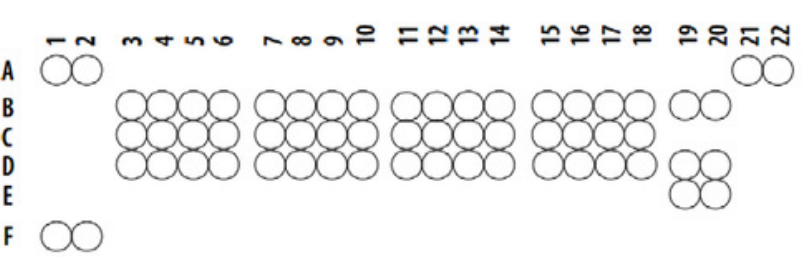

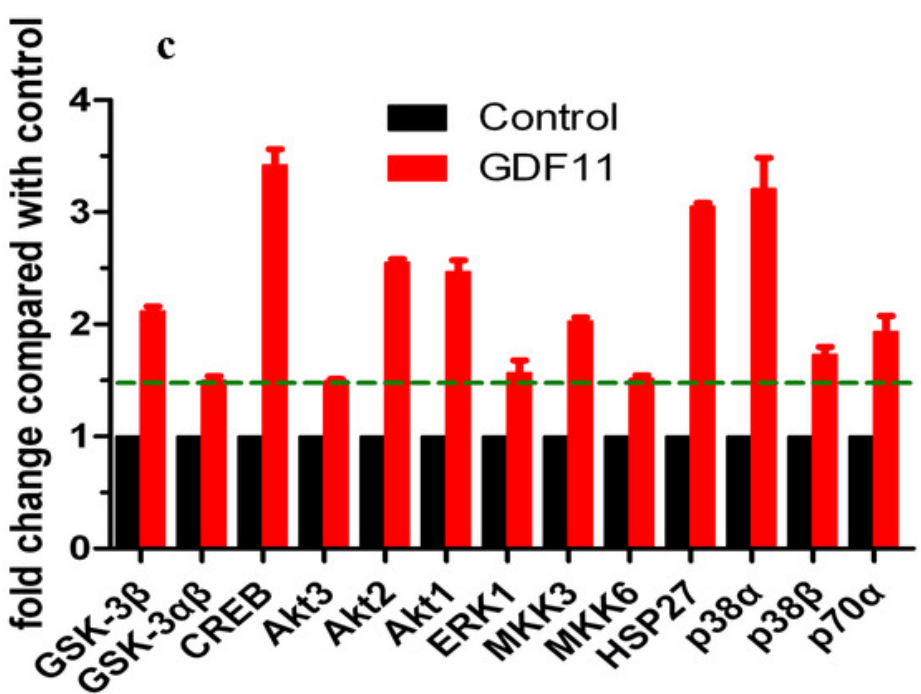




\section{Figure 6}

Functional classification and protein-protein interaction of the differentially expressed proteins in GDF11-treated C17.2 cells and control.

(a). According to GO annotation, the differentially expressed proteins between GDF11-treated cells and control were mainly clustered into 38 functional groups, including 18 biological processes, 12 cellular components, and 8 molecular functions. (b). Protein domain categories of the differentially expressed proteins were annotated by InterProScan. (c). The proteinprotein interaction network of the differentially expressed proteins was analyzed by KEGG) database. 

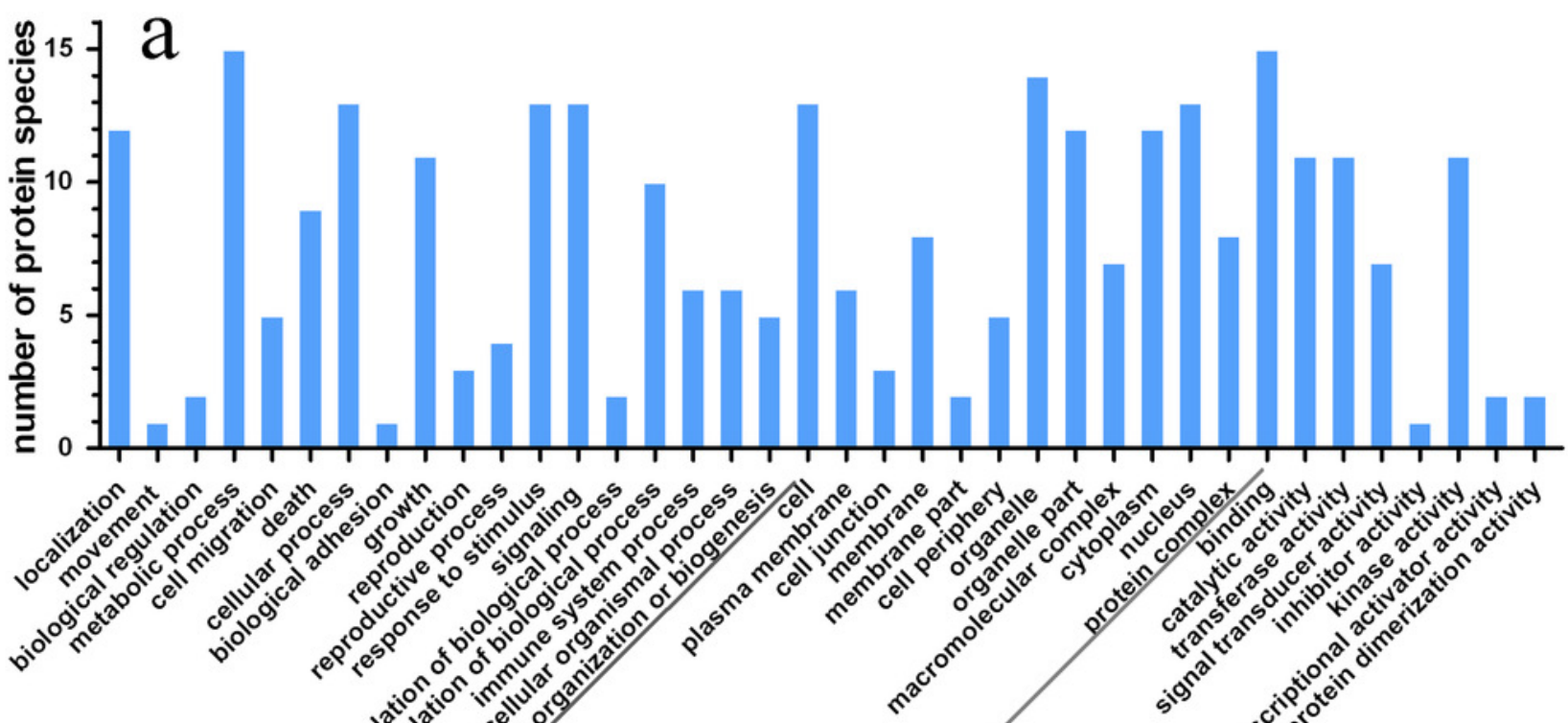

Biological Process

Cellular Component
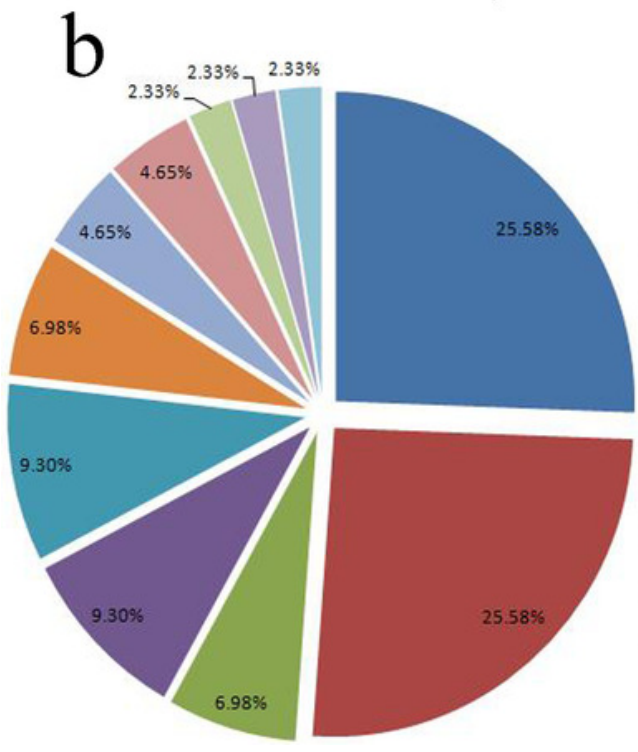

Protein kinase domain

Protein kinase-like domain

a $\mathrm{PH}$ domain-like

॥ Protein kinase

= AGC-kinase, C-terminal

= Pleckstrin homology domain

= MAD homology, MH1

"SMAD domain-like

"Alpha crystallin $/ \mathrm{Hsp} 20$ domair

= Basic-leucine zipper domain

w Coactivator CBP, pKID

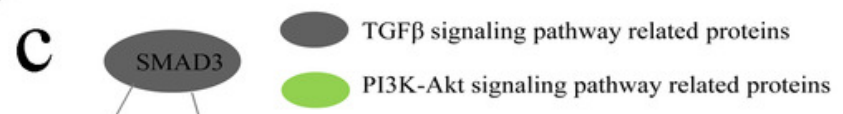

Molecular Function

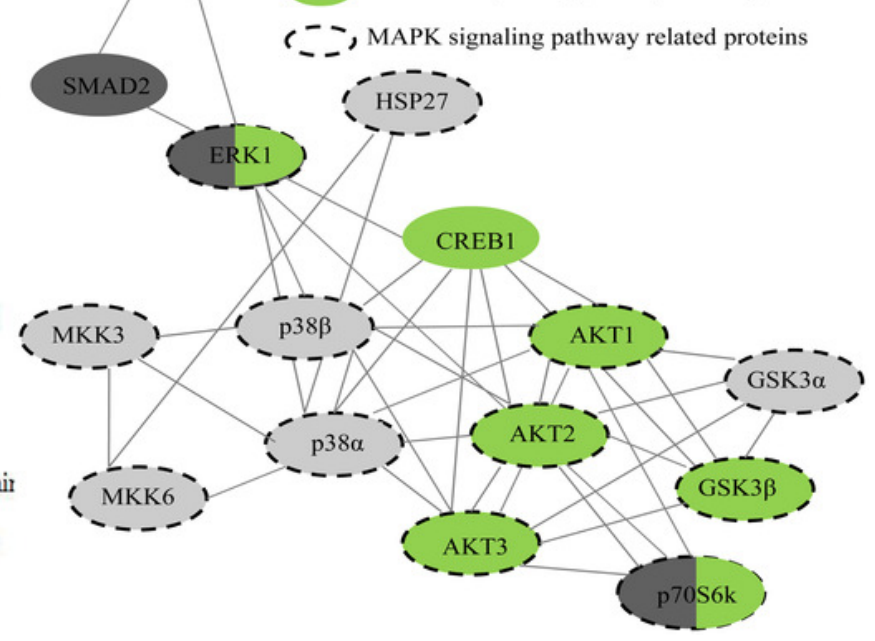




\section{Table 1 (on next page)}

The subcellular location of the differentially expressed proteins 
1

\begin{tabular}{ccc}
\hline Proteins & Subcellular Location & Fold Changes \\
\hline GSK-3 $\beta$ & cytoplasm & 2.12 \\
GSK-3 $\alpha$ & nucleus & 1.50 \\
CREB & nucleus & 3.42 \\
Akt2 & cytoplasm & 2.55 \\
Akt1 & cytoplasm & 2.47 \\
ERK1 & cytoplasm & 1.57 \\
MKK3 & nucleus & 2.03 \\
HSP27 & nucleus & 3.05 \\
P38 $\alpha$ & cytoplasm & 3.21 \\
p38 $\beta$ & cytoplasm, nucleus & 1.73 \\
p70s6k & nucleus & 1.93 \\
Smad2 & mitochondria & 1.99 \\
Smad3 & cytoplasm, nucleus & 2.01 \\
Akt3 & cytoplasm & 1.50 \\
MKK6 & cytoplasm & 1.52 \\
\hline
\end{tabular}

2 